\title{
Enlightenment of Business in China Low-Carbon Economy in Developed Countries in Various Fields of Application and Practice
}

\author{
Hongli Jiao, Juan Wang \\ Economic Management, Finance and Insurance, Bohai University, Guangzhou, 121000, China
}

\begin{abstract}
With the development of economy, it's urgent to solve the human problems that the greenhouse effect and the phenomenon caused by the greenhouse effect of a series of global climate change, moreover, there exists inevitable link between massive emissions of carbon dioxide and the global temperature rise, so it must introduce the low-carbon economy development and promotion of the concept of environmental protection. This paper first analyzes the connotation and awareness of the low-carbon economy, what's more, we can make use of data mining of low-carbon economy in developed countries in the world in various fields of practical application analysis, and then we can deepen the development of lowcarbon economic feasibility analysis model of constructing Chinese enterprises. Furthermore, we propose science countermeasures about the implementation of a low-carbon economy and provide the theoretical basis and practical decisions for the application of low-carbon economy in China and developing countries.
\end{abstract}

Keywords-developed countries;
$\begin{aligned} & \text { low-carbon } \\ & \text { application practice; Chinese } \\ & \text { countermeasures; analysis model. }\end{aligned}$

\section{INTRODUCTION}

As China is the most important manufacturing industry areas in the world, it's particularly important to balance environmental protection with the rapid economic development. In the nation, there are various ideas among experts about the development of low-carbon economy, such as Xiaomin Qiu develops countries experience in a low-carbon economy and applications in Liaoning Province and makes a brief description about the concept of the "lowcarbon economy $[1,2]$. in-depth, learning from the experience of developed countries and low-carbon economy combined with development characteristics of the study subjects; Bin Wang claims practice developed low carbon economy and its Implications for China, a solid theoretical foundation for the full implementation of a low-carbon economy is laid from the state of the environment in the world today within the analysis goal, according to the international environmental protection policies, so we can build the Chinese enterprises environmentally friendly and high-performance low-carbon economic development. Further, we can make the use of technology research and development to adapt to the background of the times, international cooperation, and advanced technological means to optimize the industrial structure as well as science policy formulation; Ying Wang introduce the European low- carbon economic development model of China's revelation, at the same time. To this end, the state and society pay close attention to climate warming, and aiming at existing social and economic development mode, to carry out a profound reflection [3]. Therefore, a low carbon economy as economic development mode of the basic goal has obtained the universal approval of state and the society, which is the new era of human and natural development goals. Under the perspective of low carbon economy, the main content of economic development patterns has: (1) the traditional development concept towards scientific technology development concept transformation. First of all, the change of economic development concept, the seriously implement of the scientific technological development, forming a harmonious society; (2) the concept of traditional development towards a low carbon economy theory transformation, namely in the capital investment process, which not only contains monetary, human capital and other large amount of investment, but also need to have the natural environment capital investmen; First, the resource can be performed recycling, to fully enhance the comprehensive utilization efficiency, greatly reducing the industrial, natural and waste emissions, reducing the damage of the natural environment. Second, it can coordinate the relationship between human and nature, to carry out digital simulation for the movement ways and the change regularity of the natural environment ecological system, and fully sustainable utilization for the natural resources, to achieve growth social economy, the efficient use of natural resources and the protection of natural environment, which can be economic and natural harmonious development.

\section{THE CONNOTATION AND COGNITION OF LOW-CARBON ECONOMY}

The United Kingdom firstly proposes the concept of low-carbon economy, then it is extensive researched by Europe and the United States and other developed countries [4-5]. The first one is the largest producer of low-carbon normalization of social life, and to maintain a social life energy companies operating low-carbon, which relates to national life run enterprises, government regulations and material circulation in areas, such as the development of low-carbon economy about the actual sense of the world and China.

As Figure 1 shows, there are four universal connotation of the low-carbon economy for the world and China, and 
they are set to $\left\{\xi_{n}\right\}$, which is an independent and identically distributed random variables sequence, moreover, the actual economic development evaluation:

$$
E\left(\xi_{n}\right)=\mu D\left(\xi_{n}\right)=\sigma^{2}>0, n=1,2, \cdots
$$

For ordinary people, it is necessary to pay attention to the needs and preferences of the individual consumer in the environment of a low-carbon economy, and to maximize the power of individuals which can reduce the use of noncarbon products and change the traditional consumption habits. Government policy mechanisms need laws and regulations of government agencies and departments to develop, $\forall x \in R$ then:

$$
\lim _{n \rightarrow+\infty} P\left\{\frac{\sum_{k=1}^{n} \xi_{k}-n \mu}{\sigma / \sqrt{n}}<x\right\}=\frac{1}{\sqrt{2 \pi}} \int_{-\infty}^{x} e^{-\frac{t^{2}}{2}} d t
$$

Developed countries recognize the carbon dioxide emissions for the greenhouse effect which produces a negative feedback, and the development of low-carbon economy advantage is much higher than the proportion of the development of high energy consumption in developing countries. Frequency independent connotation occurrence of re-development of the low-carbon economy is $\frac{v_{n}}{n}$, the convergence in probability in the probability of events in each experiment is $P$, namely $\forall \varepsilon>0$

$$
\lim _{n \rightarrow+\infty} P\left\{\left|\frac{v_{n}}{n}-p\right|<\varepsilon\right\}=1
$$

In formula (3), compared with the high-carbon economy, low-carbon economy of mass production in today's society reduces the advent of high energy consumption products and high-energy consumption trade between countries; Based on the operation of the low-carbon economy, it' $s$ vigorous to develop on the basis of renewable, energy-based, low-power and high-tech green resources, which is one of the important goals about the development of low-carbon economy.

\section{APPLICATION AND PRACTICAL STRATEGIC ANALYSIS OF LOW-CARBON ECONOMY IN DEVELOPED COUNTRIES}

\section{A. The world's low-carbon economy strategy for the application of economic advances}

Since the concept of low-carbon economy is proposed in the UK, the development of low-carbon economy is a hot topic in the various countries of the world, which is the earliest concept of a low-carbon economy written into the government documents in British, obviously, it has become a well-deserved world advocates of a low-carbon economy and pioneer. Britain has spoken out the low-carbon economy as the country's development strategy since 2003, actually, British has on their own low-carbon economy, moreover, the development of low-carbon chain increasingly tends to optimize the direction of development, and is well received by the public. Since 2003, there are four levels in the field of low-carbon economy of the British strategy, as shown in Figure 1.

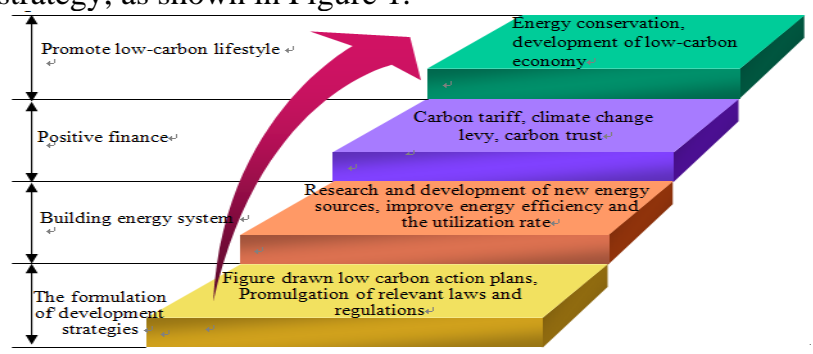

Figure 1. The world's low-carbon economy first low-carbon economy applications strategy

As Figure 2 shows, the world's low-carbon economy first country, Britain, its low-carbon economic strategy for the application is divided into four progressive levels, which are in the system to provide operational support of lowcarbon economy, and actively develop new energy innovation in low-carbon economy, so that it provides favorable conditions. The government issues the low carbon transition plan, renewable energy strategic decision based on the actual conditions and policies that encourage people to choose low-carbon lifestyle, which vigorously changes lifestyle and comprehensively promotes the UK into the low-carbon economic powers.

\section{B. Low-carbon economy strategy for the application of other developed countries.}

Developed countries which have more mature understanding of the low-carbon economy tend to regard low-carbon economy as the economic development of their characteristics. The developed countries, like Germany, United States of America, Japan, make use of the national low-carbon economic strategy for the application relating to policies and regulations, low-carbon technologies, people's lifestyle, financial means, specifically as shown in Figure 2.

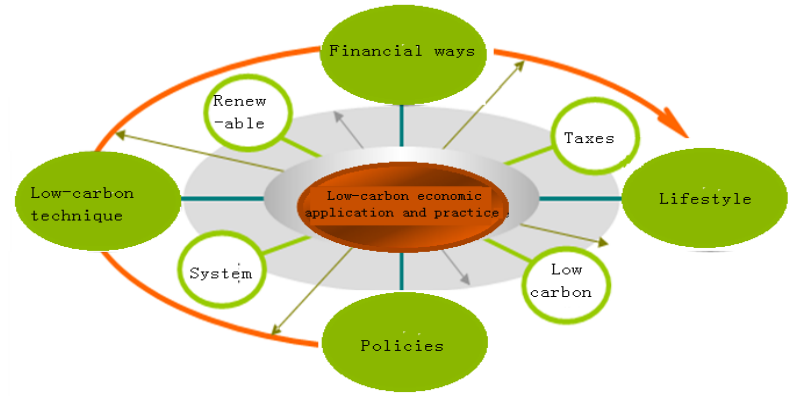

Figure 2. Low-carbon economy strategy for the application of other developed countries

As Figure 3 shows, the level of low-carbon strategy of developed countries involves a wide range, such as Germany, it vigorously develops renewable resources for the country's industries by establishing a series of environmental protection policies and promoting a low- 
carbon economy in the a long time ago; Since 2005 the United States gradually has increased the importance of green energy and low-carbon economic development. Island nations like Japan also strongly advocate a low-carbon economy and energy saving plan, and take a combination of technical and institutional innovation.

\section{LOW-CARBON ECONOMIC FEASIBILITY OF THE DEVELOPMENT OF CHINESE ENTERPRISES AND COUNTERMEASURES}

Rubin de (British environmental experts) claims the lowcarbon economy is an economic model that has a broad space for development, the core-based market mechanism, under which government policy measures and corporate framework system combined to produce green energy savings and initiative behavior to energy-saving technologies applied to life, to reduce greenhouse gas emissions, the development of the world toward a new lowcarbon economy and society of high efficiency, low energy consumption and low emissions. Low-carbon development is a clear understanding of the relationship between sustainable development and low-carbon development, there exists need to establish a mechanism for long-term adherence. Located in the Chinese enterprises to the development of low-carbon economy strategic decision is independent and identically distributed random variable sequence $\left\{\xi_{n}\right\}$ and

$$
\xi_{n} \sim B(1, p),(0<p<1, n=1,2, \cdots)
$$

Then $\forall x \in R$,

$$
\lim _{n \rightarrow+\infty} P\left\{\frac{\sum_{k=1}^{n} \xi_{k}-n p}{\sqrt{n p(1-p)}}<x\right\}=\frac{1}{\sqrt{2 \pi}} \int_{-\infty}^{x} e^{-\frac{t^{2}}{2}} d t
$$

Under the leadership of the socialist system with Chinese characteristics, China is forward industrialization and urbanization. The rapid social development and the rapid GDP increasingly consume up. That the distribution $\chi^{2}$ can be added to set the random variables $\chi_{k}^{2} \sim \chi^{2}\left(n_{k}\right), k=1,2, \cdots, n$,then:

$$
\chi^{2}=\sum_{k=1}^{n} \chi_{k}^{2} \sim \chi^{2}\left(\sum_{k=1}^{n} n_{k}\right)
$$

While economic stability and development is safeguarded, it's essential to base on the overall construction of the ecological environment, however ,Chinese enterprises is still facing numerous challenges under the development of low-carbon economy in the context of the socialist economic system. If the random variable $\chi^{2} \sim \chi^{2}(n)$, then:

$$
\frac{\chi^{2}-n}{\sqrt{2 n}} \stackrel{L}{\rightarrow} N(0,1)
$$

During the Party's "Eighteen" meeting, it adds the basis of the concept of ecological civilization in the original "Four in One", and ultimately the formation of the overall layout of the "five in one", the last but not the least, the visible environmental issues and the development of low-carbon economy has become a national building an important task. If the random variable $\chi^{2} \sim \chi^{2}(n)$, then:

$$
\sqrt{2 \chi^{2}}-\sqrt{2 n-1} \rightarrow N(0,1)
$$

In order to enhance the information and the determination of the Chinese enterprises developing lowcarbon economy,. According to China's energy structure, it' s important to analysis developed feasibility science countermeasures program in the fairness of the constraints of the traditional system based on. Let random variables $\xi$, $\eta$ are independent of each other $\xi \sim N(0,1), \eta \sim \chi^{2}(n)$ and the random variable expression:

$$
t=\frac{\xi}{\sqrt{\eta / n}}
$$

It's the only way to realize the development of renewable green energy, which we can tackle through improved energy efficiency when we face the future of the Chinese enterprises. Obedience distribution called freedom $n$ distribution of $t$, denoted $t \sim t(n)$, adding that it is the degree of freedom $n$ for the variable $t$. The following table shows the development of low-carbon economy in the developed countries of China and the Chinese enterprises revelation.

TABLE I. THE DEVELOPMENT OF LOW-CARBON ECONOMY OF CHINA AND CHINESE ENTERPRISES REVELATION IN DEVELOPED COUNTRIES

\begin{tabular}{|c|l|l|}
\hline Number & \multicolumn{1}{|c|}{ Revelation } & \multicolumn{1}{|c|}{$\begin{array}{c}\text { Strategic } \\
\text { responses }\end{array}$} \\
\hline 1 & $\begin{array}{l}\text { Guided by the government to implement a long-term } \\
\text { and stable policy support }\end{array}$ & $\begin{array}{l}\text { Research and } \\
\text { introduction of } \\
\text { low-carbon } \\
\text { technique }\end{array}$ \\
\hline 2 & $\begin{array}{l}\text { Strengthen environmental education to foster public } \\
\text { low-carbon sense of participation }\end{array}$ & $\begin{array}{l}\text { System tool to } \\
\text { select low-carbon } \\
\text { economy }\end{array}$ \\
\hline 3 & $\begin{array}{l}\text { Implementation of environmental economic policies } \\
\text { to promote the development of low-carbon economy }\end{array}$ & $\begin{array}{l}\text { To change the } \\
\text { indribution of the } \\
\text { industry value } \\
\text { chain }\end{array}$ \\
\hline 4 & $\begin{array}{l}\text { To increase investment in research and development } \\
\text { of low-carbon technologies in order to promote } \\
\text { industrial restructuring }\end{array}$ & $\begin{array}{l}\text { Reduce energy } \\
\text { consumption } \\
\text { industries }\end{array}$ \\
\hline
\end{tabular}

In conclusion, China's social enterprise development of low-carbon economy is to adhere to the Green concept of sustainable development, using a variety of techniques to achieve low-carbon business operations, to reduce the high energy consumption enterprises running efforts to solve the low-carbon economic development, social environment and natural resources of the three the contradictions. 


\section{CONCLUSIONS}

With the opportunities and challenges in the era of rapid economic development and the use of energy, the energy problem has become one of the important factors restricting economic development and has affected the development of society from production, life and other aspects. In order to make unremitting efforts for the comprehensive development of low-carbon economy and promote the rapid growth of the enterprise, it's indispensable to emphasize the development of low-carbon technologies, strengthen national scientific and technological cooperation, further, optimize the structure of production and the development of scientific and rational protection policies and measures.

\section{ACKNOWLEDGEMENTS}

The research work was supported by Chinese Higher Occupation Technique Education Research Association "Twelfth Five-Year Plan" project (GZYLX2011076)

\section{REFERENCES}

[1] Huang Tianwei, Liu Rongzhi, Chen Su, "Research on the Development Strategies of Regional Industrial Cluster based on the Low-Carbon Perspective", AISS, Vol. 4, No. 17, pp. 165 - 173, 2012.

[2] Philip Cooke, "Transition regions: Regional-national eco-innovation systems and strategies",Progress in Planning, Vol. 76, No. 3, pp. 105146, 2011.

[3] Xiaohua Song, Pie Zu, Dan Zhao, "A combined forecasting model with variable weights for long-term electricity demand under lowcarbon economy", JDCTA, Vol. 7, No. 1, pp. 159 -166, 2013.

[4] Jerome C. Glenn, Theodore J. Gordon, "The Millennium Project: Challenges We Face at the Millennium",Technological Forecasting and Social Change, Vol. 66, No. 3, pp. 129-312, 2011.

[5] Håkon Ursin Steen, "Indicators of development or dependency in disguise? Assessing domestic inventive capacity in South Korean and Chinese infrastructural ICT standards",Telecommunications Policy, Vol. 35, No. 7, pp. 663-680, 2011. 